(2) Open Access Full Text Article

\title{
Knowledge, Perception, and Application of Pharmacogenomics Among Hospital Pharmacists in Saudi Arabia
}

This article was published in the following Dove Press journal: Risk Management and Healthcare Policy

\section{Mohammed Algahtani \\ Department of Pharmaceutics, College of Pharmacy, Najran University, Najran, Kingdom of Saudi Arabia}

Introduction: The accelerated transformation in the healthcare system supported by the Saudi Vision 2030 makes the present the best time to start the real application of pharmacogenomics in Saudi Arabia. The current study aimed to assess the knowledge, perception and the application status of pharmacogenomics among pharmacists in the hospital settings in Saudi Arabia.

Methods: This cross-sectional observational survey was conducted among 206 qualified pharmacists working in Saudi hospitals. A self-administered questionnaire was sent to all participants.

Results: Only $30 \%$ of the pharmacists had received any type of formal training on PGx. Of these, only nine participants had actually put the knowledge into practice. Participants showed a moderate to low level of knowledge when responded to the pharmacogenomic knowledge indicators used in the study. The low knowledge and the availability of the pharmacogenetic test are the main barriers for the low adoption of the pharmacogenomics in the clinical practice. Approximately $83 \%$ felt the need to know more about pharmacogenomics. Participants show positive perception with high motivation levels to incorporate this technology in practice. For example, $76 \%$ stated that pharmacogenetic testing should be applied to pharmacy practice. Around $38 \%$ of participants reported that the Saudi government and the Saudi FDA had been promoting the pharmacogenomics. However, $50 \%$ of the total participants reported that their hospital management is unaware of the pharmacogenomics importance in clinical practice.

Discussion: This study emphasizes on two needs which can help promote the use and implementation of pharmacogenomics. One is the need to update the pharmacy education and training programs with pharmacogenomic-related areas to raise the pharmacist's knowledge and practical skill to apply pharmacogenomics in the clinical practice effectively. Another need is to increase the awareness of the decision and policy-makers with the importance of pharmacogenomics for the patient benefit and safety. This preliminary evaluation will provide future insight into the best approach to applying pharmacogenomics in the Saudi healthcare system.

Keywords: pharmacogenomics, pharmacogenetics, Saudi Arabia, knowledge, attitude, implementation, pharmacists

\section{Introduction}

The paradigm shift from "one size fits all" to the precise, personalized regime of modern medicine strategy in healthcare has led the focus on PGx. This pragmatic approach, first published by Vogel in 1959, involves the use of genetic information
Correspondence: Mohammed Algahtan Email msalqahtane@nu.edu.sa
Risk Management and Healthcare Policy 2020:|3 |279-129| 
for better pharmacotherapy outcomes. ${ }^{1,2}$ The combination of pharmacology (drugs science) and genomics (genes and their functions) forms pharmacogenomics (PGx). ${ }^{3}$ The advantages of PGx include the reduction of health care costs by reducing adverse drug reactions and the number of failed trials, less time required for drug approval, and less need to try several medications to find the one with the best results for the patient. ${ }^{4}$

The previous years have witnessed approximately $15 \%$ of the medications approved by FDA (US Food and Drug Administration) and EMA (European Medicines Agency) having PGx information on their drug labels; only a few make it to clinical consideration. ${ }^{2,5,6}$ Further, rapid testing technologies and development of genotype programming indicate PGx as a feasible option for providing personalized medicine. However, slow implementation of PGx by the pharmaceutical and health care sector could be attributed to barriers like lack of knowledge, awareness and the extent of confidence of the healthcare practitioners to implement this technique. The limited resources and the availability of the PGx tests also considered as obstacles need to be overcome. ${ }^{4,7}$

Even though PGx training among pharmacists is being implemented in certain developed nations like the USA and countries in Europe, developing countries are lagging in creating awareness. ${ }^{8-10}$ For example, previous evidence has reiterated the poor understanding of PGx among pharmacists in Australia and the limited resources for creating awareness in Zimbabwe. ${ }^{11,12}$ In 2015, a systematic review was conducted to assess knowledge, attitude, and practice concerning PGx among pharmacists, and indicated knowledge advancement from $38 \%$ in 2005 to more than $50 \%$ in 2013 across some countries. The studies in that review indicated good attitude, but poor knowledge and practices among pharmacists. ${ }^{13}$

One study conducted in the US examined 580 community pharmacists, and indicated that $87 \%$ had a positive attitude toward pharmacogenetic testing, but only around half of them were aware of their role in providing counseling to patients about PGx. ${ }^{14}$ A study conducted in Australia had concurrent views, as the majority of pharmacists did not believe in their capability to counsel the patients about pharmacogenetic testing. ${ }^{11}$ Further, a study conducted in Indonesia among 60 community pharmacies and 11 clinic and hospital pharmacies surprisingly found more awareness among community pharmacists than those in hospital settings. ${ }^{15}$ Among Middle Eastern countries, a study conducted in Qatar found low awareness among both among pharmacists and doctors about the applications of PGx. However, the pharmacists had a more positive attitude about PGx application in their daily practice than the doctors. ${ }^{16}$

Pharmacists have the potential to influence educators, clinical consultants, and health care providers about the importance of PGx in healthcare. Pharmacists trained in PGx have contributed to improving medication compliance among patients by providing tailor-made solutions for drug administration as per individual patient needs. They contribute to genetic testing, counseling of patients, and selection of drug therapies for better treatment outcomes. ${ }^{17,18}$

PGx is gaining momentum in the Middle East, and three foundational genomic research initiatives are underway in the countries of the Gulf Cooperation Council (GCC), which includes the Kingdom of Saudi Arabia (KSA). These initiatives include the catalogue of transmission genetics in Arabs (CTGA) hosted by the Centre for Arab Genomic Studies in the United Arab Emirates, the Qatar Biobank Initiative, and the Saudi human genome program (SHGP). The CTGA online data focuses on the genetic composition of diseases across the Arab world and is applied for genomic medicine among their patients. ${ }^{19,20}$ SHGP aims to investigate endemic disease with a strong genetic component, such as diabetes, cardiovascular disease, neurodegeneration, cancer, and inherited Mendelian disorders. $^{21}$

Saudi Arabia has a high risk of genetic diseases, including inherited diseases that appear at an early age and have an impact on of $8 \%$ of births, and chronic diseases which occurs later in life, such as cardiovascular, neurological diseases and obesity/diabetes, which ultimately affect more than $20 \%$ of the population. ${ }^{21}$ Firstcousin marriages represent more than $50 \%$ of the marriages in the Saudi population, leading to both common and unique genetic disorders. ${ }^{22}$ The genetic polymorphisms of cytochrome P450 (CYP450) enzymes greatly influence the safety and efficacy of drug treatment. ${ }^{23}$ CYP2C is a subfamily of CYP450 which influences the metabolism of around $20 \%$ of drugs including anticoagulants and anti-diabetic drugs and non-steroidal antiinflammatory drugs. ${ }^{24} \mathrm{CYP} 2 \mathrm{C} 9 * 2$ and $\mathrm{CYP} 2 \mathrm{C} 9 * 3$ are alleles responsible for reduced CYP2C9 activity which led to an increase in the activity of anticoagulant drugs like warfarin. ${ }^{24}$ In Saudi, CYP2C $9 * 2$ and CYP2C $9 * 3$ were reported in Riyadh with frequencies $11 \%$ and $9 \%$, respectively. ${ }^{25}$ In $\mathrm{Al}$-Ahsa city, $\mathrm{CYP} 2 \mathrm{C} 9 * 2$ and 
CYP2C9*3 also reported with frequencies around 13\% and $2.3 \%$, respectively. ${ }^{26}$ Saudi patients with CYP2C9*2 and CYP2C9*3 alleles had more bleeding incidence and required dose adjustment by $40 \%$ less of the regular effective dose. ${ }^{25}$ Keeping these disorders in mind, PGx has an important role to play in Saudi Arabia by focusing on genomic classifications and epigenetic, idiopathic, and personalized medicine. The genetic variations in Saudi Arabia make it vital for pharmacists to be actively involved in PGx..$^{21,27}$

The use of PGx in medicine is a milestone and can be accomplished effectively by harnessing established resources in the form of qualified pharmacists. However, the implementation of this new field has to be backed up and governed by strong policy and health sector reforms. For instance, in Saudi Arabia, the Ministry of Health $(\mathrm{MoH})$ is accountable for developing health-related laws and regulations for both the governmental and private sectors, along with monitoring the performance of healthcare institutions. The Saudi FDA assesses the safety and efficacy of drugs before licensing them for marketing. Therefore, it is imperative to have approval and support from both of these governing bodies for establishing PGx in the Kingdom.

With this background, the current study aimed to assess the knowledge, awareness, and attitude of pharmacists in hospital settings toward pharmacogenetics in all the hospitals in Saudi Arabia. It also aimed to gain a better understanding of the factors associated with the pharmacists' knowledge and perceptions of the same. This study is unique, as it is one of the first studies conducted in Saudi Arabia examining these issues.

\section{Materials and Methods Participants}

The sample consisted of 206 pharmacists practising in Saudi MoH hospitals, other governmental hospitals, and private Saudi hospitals. The study protocol was approved by the Research Ethical Committee, Najran University Ref. No: 20-1-1-20 ET. The participants were assured that no harm would occur if they decided to participate in this study. Their participation in the study was voluntary, and they were free to leave the study at any point of time without repercussions. They were also assured that their responses would be both anonymous and confidential. Their agreement to participate was considered as consent.

\section{Procedure}

A web-based survey was administered online, using Google Forms. The practising hospital pharmacists were invited to respond to the survey through two platforms: Twitter and WhatsApp. Two criteria were used to send the invitations to Twitter users: the user identified him- or herself in the account bio as a hospital pharmacist in Saudi Arabia, and the direct message for the account was open and received messages. For WhatsApp, the invitation was sent to groups that were generated for hospital pharmacist affairs in Saudi hospitals. Such WhatsApp groups are non-official groups generated by hospital pharmacists, and any pharmacists can join for networking and discussions.

The invitation included a brief definition of pharmacogenetics, the objectives of the study, and the survey hyperlink. The estimated number of hospital pharmacists who received the survey invitation through direct message on Twitter and the number of WhatsApp group participants was around 1200 .

The survey was open for respondents from Feb 10 until Mar 3, 2020. Three reminders to complete the survey were sent to the same Twitter accounts and WhatsApp groups. The respondents were informed that the survey would take around five to six minutes to complete. Out of the approximately 1200 pharmacists invited to participate, 206 (17\%) completed the survey.

\section{Materials}

The questionnaire consisted of 36 questions divided into the following sections (Supplemental material):

Section a: Socio-demographic profile: This included information like name, age, and gender, along with educational and professional qualifications and experience.

Section b: Knowledge regarding PGx was assessed, pertaining to genetic determinants, pharmacogenetics testing, the role of PGx in patient's life, role in the identification of drug interactions, etc.

Section c: Pharmacists' perceptions regarding PGx were evaluated in terms of the importance of pharmacogenetics in their daily practice and their involvement and expectations.

Section d: Application of PGx in practice was assessed based on their knowledge application of pharmacogenetics and its implementation in a real-world scenario.

The survey was written in English and accompanied by an Arabic translation, as the native language of most of the 
targeted population. Three experts were appointed to review the accuracy of the Arabic translation. Respondent's answers were in the form of a predefined set of answers on a Likert scale.

\section{Data Analysis and Statistics}

SPSS software (ver. 23; IBM SPSS Inc., Chicago, IL) was used for the statistical analyses. The analysis description was figured out using tables for numeric data and frequency (n) and percentage (\%) for categorical data. The Chi-square test, Fisher's exact, and Wilcoxon rank-sum test were used to assess associations between categorical variables. Statistical significance was set at $\mathrm{P}<0.05$. The Socio-demographic details of the participants are presented in Table 1.

\section{Results}

\section{Socio-Demographic Characteristics}

The present study was conducted with 206 participants. The majority of the participants had a BSc degree as an educational qualification (83, 40.3\%), Pharma D (25.7\%), about 49 (23.8\%) were qualified up to MSc, and rest were PhD qualified (10.2\%). About 92 participants (44.7\%) had obtained their degree within five years of conducting this survey. The majority of the participants worked as Pharmacists, and the rest worked as Senior or Consulting Pharmacists. Table 1 presents the participants' demographic and professional data.

As depicted in Table 1, most of the pharmacists were working in $\mathrm{MoH}$ health settings $(n=123,60 \%)$. One hundred forty-four participants $(69.9 \%)$ did not receive any formal training on PGx; 53 participants had either received training or heard about the concept during pharmacy education (35.8\%), followed by scientific conferences $(22.6 \%)$, and hospital seminars or past research $(15.1 \%)$ (Figure 1). The pharmacogenetic test adoption was recently ordered $(<$ six months back from the time of the survey) by only eight participants.

\section{Knowledge Regarding PGx}

Six parameters were included in order to assess the study participants' knowledge about PGx (Table 1). Four knowledge indicators were answered correctly by more than half of the participants. The first indicator was knowledge of whether applying PGx in practice would influence the patient's adherence to drugs; 127 of the participants $(61.6 \%)$ answered this statement correctly. Among them,
Table I Socio-Demographic Details of Study Participants $(\mathrm{N}=206)$

\begin{tabular}{|c|c|c|c|}
\hline $\begin{array}{l}\text { Socio- } \\
\text { Demographic } \\
\text { Characteristics }\end{array}$ & & $\begin{array}{l}\text { Number } \\
(N=206)\end{array}$ & $\begin{array}{l}\text { Percentage } \\
\text { (\%) }\end{array}$ \\
\hline $\begin{array}{l}\text { Educational } \\
\text { qualification }\end{array}$ & $\begin{array}{l}\text { BSc } \\
\text { MSc } \\
\text { Pharm D } \\
\text { PhD }\end{array}$ & $\begin{array}{l}83 \\
49 \\
53 \\
21\end{array}$ & $\begin{array}{l}40.3 \\
23.8 \\
25.7 \\
10.2\end{array}$ \\
\hline $\begin{array}{l}\text { Number of years } \\
\text { since completed } \\
\text { the last degree }\end{array}$ & $\begin{array}{l}<2 \\
2 \text { to } 4 \\
5 \text { to } 7 \\
8 \text { to } 10 \\
>10\end{array}$ & $\begin{array}{l}49 \\
43 \\
43 \\
35 \\
36\end{array}$ & $\begin{array}{l}23.8 \\
20.9 \\
20.9 \\
17.0 \\
17.5\end{array}$ \\
\hline $\begin{array}{l}\text { Current } \\
\text { designation }\end{array}$ & $\begin{array}{l}\text { Pharmacist } \\
\text { Senior } \\
\text { pharmacist } \\
\text { Consultant } \\
\text { pharmacist }\end{array}$ & $\begin{array}{l}134 \\
53 \\
19\end{array}$ & $\begin{array}{l}65.0 \\
25.7 \\
9.2\end{array}$ \\
\hline Work setting & $\begin{array}{l}\text { MoH Hospitals } \\
\text { Other } \\
\text { governmental } \\
\text { hospitals } \\
\text { Private hospitals }\end{array}$ & $\begin{array}{l}123 \\
69 \\
14\end{array}$ & $\begin{array}{l}59.7 \\
33.4 \\
\\
6.7\end{array}$ \\
\hline $\begin{array}{l}\text { Whether received } \\
\text { any formal training } \\
\text { on PGx }\end{array}$ & $\begin{array}{l}\text { Yes } \\
\text { No } \\
\text { Maybe }\end{array}$ & $\begin{array}{l}53 \\
144 \\
9\end{array}$ & $\begin{array}{l}25.7 \\
69.9 \\
4.4\end{array}$ \\
\hline $\begin{array}{l}\text { Whether aware of } \\
\text { drug-gene } \\
\text { interaction }\end{array}$ & $\begin{array}{l}\text { Yes } \\
\text { No } \\
\text { Maybe }\end{array}$ & $\begin{array}{l}109 \\
74 \\
23\end{array}$ & $\begin{array}{l}52.9 \\
35.9 \\
11.2\end{array}$ \\
\hline $\begin{array}{l}\text { Whether you } \\
\text { ordered PGx test } \\
\text { recently? }\end{array}$ & $\begin{array}{l}\text { Maybe } \\
\text { No } \\
\text { Yes } \\
-<6 \text { months back } \\
->\text { I year back }\end{array}$ & $\begin{array}{l}3 \\
194 \\
9 \\
8 \\
1\end{array}$ & $\begin{array}{l}1.4 \\
94.2 \\
4.4 \\
88.9 \\
11.1\end{array}$ \\
\hline
\end{tabular}

there were 83 of the Pharmacists $(n=134,62 \%), 34$ of the Senior Pharmacists $(n=53,64 \%)$, and 10 of Consultant Pharmacists $(\mathrm{n}=19,52.6 \%)$. Also, around three-quarters of the participants $(151,73.3 \%)$ answered correctly that PGx is important to identify drug-drug interactions. The correct answer was given by 94 of the Pharmacists ( $n=134$, $70 \%), 42$ of the Senior Pharmacists $(\mathrm{n}=53,79 \%)$, and 15 of the Consultant Pharmacists ( $\mathrm{n}=19,80 \%)$. The knowledge indicator that the warfarin package insert warns that specific genetic variants might alter the warfarin metabolism was answered correctly by $(121,58.7 \%)$ of total participants. This correct information selected by 73 


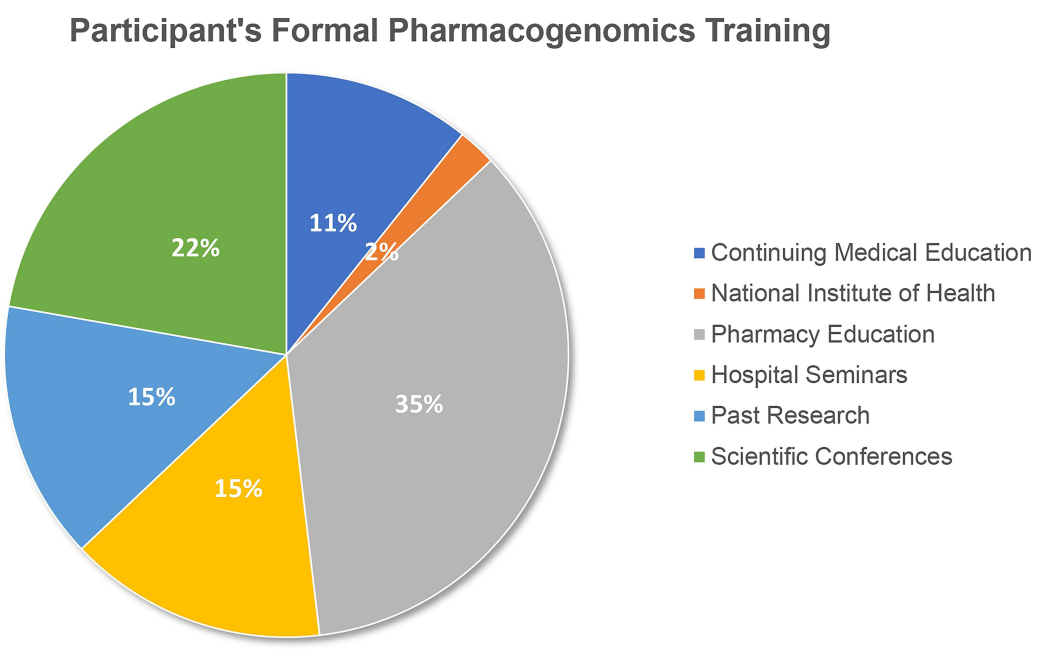

Figure I Sources of participants training in PGx $(N=53)$.

Pharmacists $(\mathrm{n}=134,54.4 \%), 36$ Senior Pharmacists $(\mathrm{n}=53,68 \%)$, and 12 Consultant Pharmacists $(\mathrm{n}=19$, $63 \%)$. Slightly above half of the participants $(109,53 \%)$ were aware of where to find drug-gene interaction in handbooks or clinical decision support. This information was known to 68 Pharmacists $(\mathrm{n}=134,50.7 \%), 31$ Senior Pharmacists $\quad(\mathrm{n}=53, \quad 58.4 \%), \quad$ and 10 Consultant Pharmacists $(\mathrm{n}=19,52.6 \%)$.
Two knowledge indicators were answered poorly by the participants (Table 2). Only $(75,36 \%)$ of the total participants answered correctly that the PGx tests are not available for most drugs. Among those who answered correctly, 40 (30\%) were Pharmacists, 24 (45\%) were Senior Pharmacists, and 11 (57\%) were Consultant Pharmacists. Only $33(16 \%)$ of the total participants were aware that the genetic determinants of drug response

Table 2 Responses to the Knowledge Indicators Based on Their Designation ( $N=206)$

\begin{tabular}{|c|c|c|c|c|}
\hline Knowledge Indicators & Response & Pharmacist & $\begin{array}{l}\text { Senior } \\
\text { Pharmacist }\end{array}$ & $\begin{array}{l}\text { Consultant } \\
\text { Pharmacist }\end{array}$ \\
\hline Pharmacogenomics will influence the patient's adherence to drugs & $\begin{array}{l}\text { Yes* } \\
\text { No } \\
\text { Maybe }\end{array}$ & $\begin{array}{l}83 \\
12 \\
39\end{array}$ & $\begin{array}{l}34 \\
5 \\
14\end{array}$ & $\begin{array}{l}10 \\
1 \\
8\end{array}$ \\
\hline Pharmacogenomics has an important role in identifying drug-drug interactions & $\begin{array}{l}\text { True* } \\
\text { False } \\
\text { Do not Know }\end{array}$ & $\begin{array}{l}94 \\
7 \\
33\end{array}$ & $\begin{array}{l}42 \\
4 \\
7\end{array}$ & $\begin{array}{l}15 \\
1 \\
3\end{array}$ \\
\hline Pharmacogenetic testing is currently available for most medications & $\begin{array}{l}\text { True } \\
\text { False* } \\
\text { Do not Know }\end{array}$ & $\begin{array}{l}29 \\
40 \\
65\end{array}$ & $\begin{array}{l}12 \\
24 \\
17\end{array}$ & $\begin{array}{l}2 \\
11 \\
6\end{array}$ \\
\hline $\begin{array}{l}\text { The package insert for warfarin includes a warning about altered metabolism } \\
\text { in individuals who have specific genetic variants }\end{array}$ & $\begin{array}{l}\text { True* } \\
\text { False } \\
\text { Do not Know }\end{array}$ & $\begin{array}{l}73 \\
4 \\
57\end{array}$ & $\begin{array}{l}36 \\
3 \\
14\end{array}$ & $\begin{array}{l}12 \\
1 \\
6\end{array}$ \\
\hline Genetic determinants of drug response change over a person's lifetime & $\begin{array}{l}\text { True } \\
\text { False* } \\
\text { Do not Know }\end{array}$ & $\begin{array}{l}62 \\
20 \\
52\end{array}$ & $\begin{array}{l}31 \\
11 \\
11\end{array}$ & $\begin{array}{l}12 \\
2 \\
5\end{array}$ \\
\hline $\begin{array}{l}\text { You are aware of drug-gene interaction in handbooks or clinical decision } \\
\text { support }\end{array}$ & $\begin{array}{l}\text { Yes* } \\
\text { No } \\
\text { Maybe }\end{array}$ & $\begin{array}{l}68 \\
48 \\
18\end{array}$ & $\begin{array}{l}31 \\
19 \\
3\end{array}$ & $\begin{array}{l}10 \\
7 \\
2\end{array}$ \\
\hline
\end{tabular}

Note: *Indicates the correct answer. 
would not change over a person's lifetime. Only 20 (15\%) who selected the correct answer were Pharmacists $(\mathrm{n}=134), 11 \quad(20.7 \%)$ were Senior Pharmacists, and 2 (10.5\%) were Consultant Pharmacists.

Follow-up pairwise comparison tests using the Wilcoxon rank-sum test showed that Pharmacists and Senior Pharmacists differed significantly in their knowledge, $p=0.043$. However, there was neither a significant difference in knowledge between Pharmacists and Consultant Pharmacists, $=0.48$ nor between Consultant Pharmacists and Senior Pharmacists, $\mathrm{p}=0.62$.

\section{Perception About PGx}

Most of the participants had a positive perception about the practical aspects of PGx in service delivery. The participants' perceptions regarding PGx are presented in Figure 2. One hundred twenty-nine, $62.6 \%$ of the total participants agreed that PGx is relevant to their pharmacy practice (Figure 3). Among these, there were 84 participants who were Pharmacists $(62.7 \%, \mathrm{n}=134), 34$ participants who were Senior Pharmacists $(64.2 \%, \mathrm{n}=53)$, and 11 who were Consultant Pharmacists $(57.9 \%, \mathrm{n}=19) \quad(P=0.833)$. Participants expressed their high need to have some knowledge about PGx (171, 83.0\%). Among these, 109 were Pharmacists $(81.3 \% \mathrm{n}=134), 44$ were Senior Pharmacists $(83 \%, \mathrm{n}=53)$, and 18 were Consultant Pharmacists $(94.7 \%$ $\mathrm{n}=19)(P=0.718)$. Two-third of the total participants $(155$, $75.2 \%$ ) agreed that pharmacogenetic testing should be applied in pharmacy practice. Among these there were 105
Pharmacists (78.4\%, $\mathrm{n}=134), 37$ Senior Pharmacists (69.8\%, $\mathrm{n}=53)$, and 13 were Consultant Pharmacists $(68.4 \%, \mathrm{n}=19)$ $(P=0.549)$.

Participants were mostly in favor of the notion that healthcare professionals should ask pharmacists about the appropriate use of PGx testing (145, 70.4\%). This belief was held by 88 of the Pharmacists $(65.7 \%, n=134), 42$ Senior Pharmacists $(79.2 \%, \mathrm{n}=53)$, and 15 Consultant Pharmacists $(78.9 \%, \mathrm{n}=19)(P=0.329)$. They also agreed with aspects like their ability to provide information on the appropriate use of pharmacogenetic testing (159, 77.2\%). Among those, there were 106 Pharmacists (79.1\%, $\mathrm{n}=134), 42$ Senior Pharmacists $(79.2 \%, \mathrm{n}=53)$, and 11 Consultant Pharmacists (57.9\%, $\mathrm{n}=19)(P=0.164)$.

Perception was high $(172,83.5 \%)$ about the ability of PGx practice to improve pharmacists' ability to control drug therapy expenditures effectively. These perceptions were held by 115 Pharmacists $(85.8 \%, n=134), 45$ Senior Pharmacists $(84.9 \%, \mathrm{n}=53)$, and 12 Consultant Pharmacists $(63.2 \%, \mathrm{n}=19)(P=0.022)$. Additionally, most participants (176, 85.4\%), including 115 Pharmacists $(85.8 \%, \mathrm{n}=134)$, 44 Senior Pharmacists $(83 \%, \mathrm{n}=53)$, and 17 Consultant Pharmacists $(89.5 \%, n=19)$, agreed that PGx testing will reduce the side effects associated with drugs $(P=0.313)$.

Figure 3 presents the expectation of the participants that PGx will prevent the giving the wrong drug or dose. Forty-six of total participants $(\mathrm{N}=206,22.3 \%)$ indicated having very high expectations of $\mathrm{PGx}$ testing in preventing administration of the wrong drug/dose. Among these there were 32

\section{Perception Parameters}

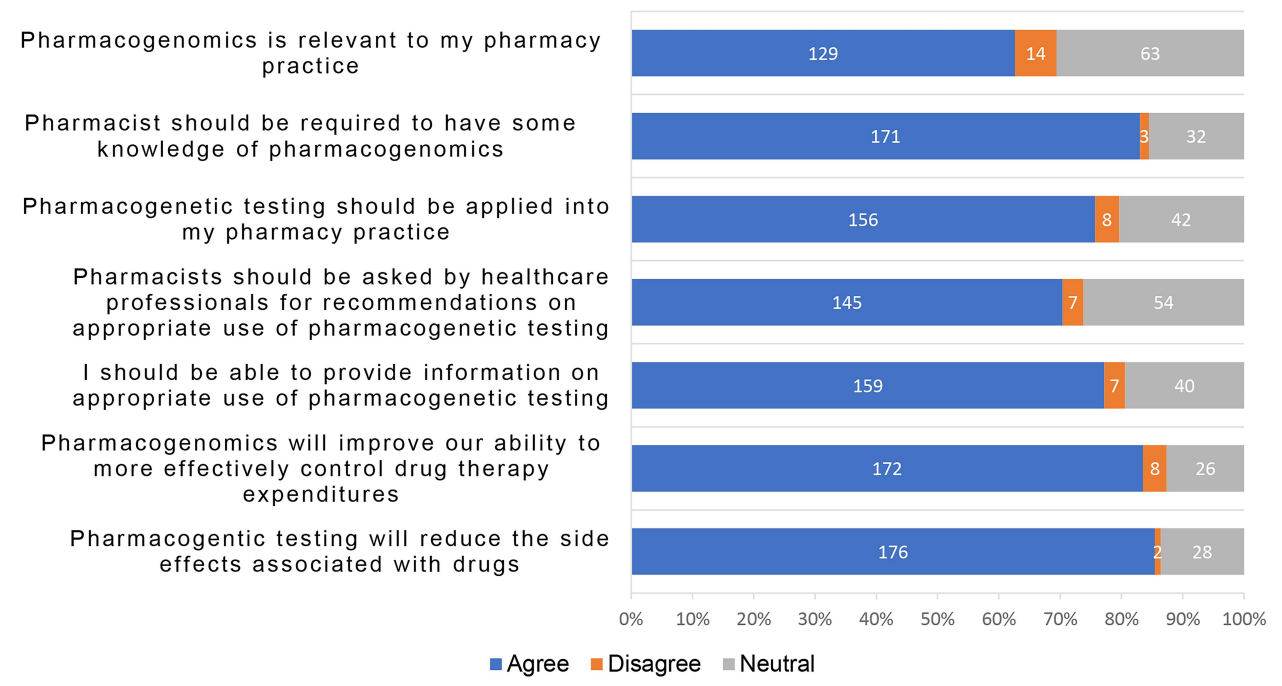

Figure 2 Perception about PGx among study participants ( $N=206)$. 


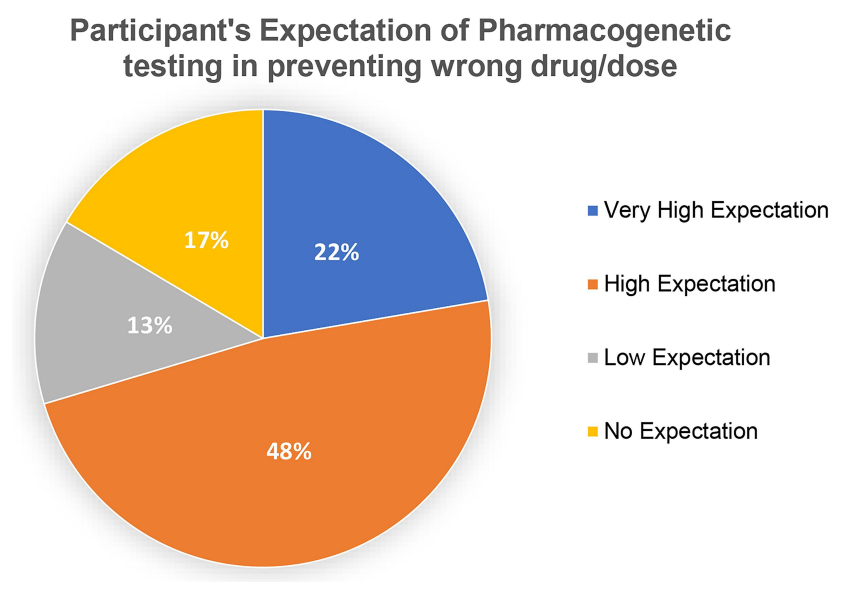

Figure 3 Participant's expectation that pharmacogenetic testing can prevent wrong drug use $(\mathrm{N}=206)$.

Pharmacists $(n=134,23.9 \%), 11$ Senior Pharmacists $(n=53$, $20.8 \%$ ), and 3 Consultant Pharmacists ( $n=19,15.8 \%)$. Ninetynine of the total participants $(\mathrm{N}=206,48.1 \%)$ comprising 68 Pharmacists $(n=134,50.7 \%), 21$ Senior Pharmacists $(n=53$, $39.6 \%)$, and 10 Consultant Pharmacists $(n=19,52.6 \%)$ indicated high expectations. Fourteen of the Pharmacists $(n=134$, $10.4 \%), 9$ Senior Pharmacists $(n=53,17 \%)$, and 4 Consultant Pharmacists $(\mathrm{n}=19,21.1 \%)$ indicated having low expectations. Furthermore, $34(16.5 \%)$ of total participants, in which there were 20 Pharmacists $(n=134,14.9 \%), 12$ Senior Pharmacists $(\mathrm{n}=53,22.6 \%)$, and 2 Consultant Pharmacists $(\mathrm{n}=19,10.5 \%)$ have no expectations $(P=0.452)$.

In addition, Figure 4 shows that 94 of total participants $(\mathrm{N}=206,45.6 \%)$, including 55 Pharmacists $(\mathrm{n}=134,41 \%), 29$ Senior Pharmacists $(\mathrm{n}=53,54.7 \%)$, and 10 Consultant

\section{Participant's Perception of Pharmacogenetic Testing} to Reveal Risk Factors of Other Diseases

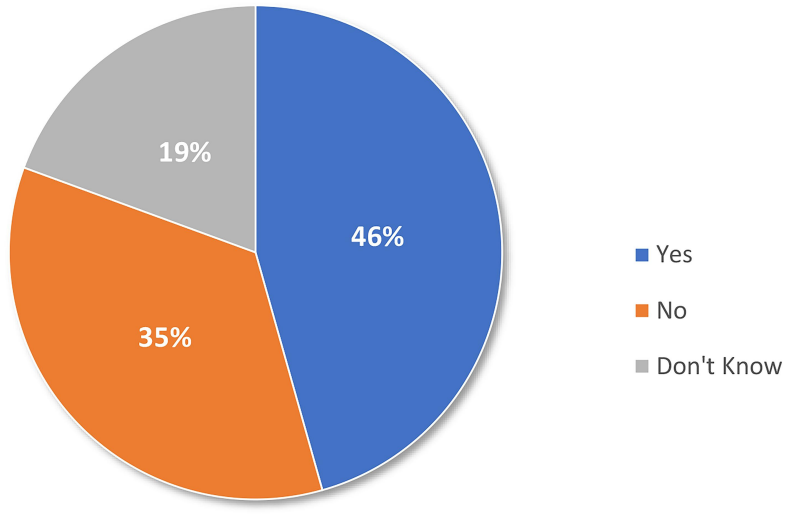

Figure 4 Participant's perception that pharmacogenetic testing could detect the patient's risk factors for another disease $(\mathrm{N}=206)$.
Pharmacists $(n=19,52.6 \%)$ were worried that PGx tests could reveal risk factors of other diseases. However, 47 (35.1\%) Pharmacists, 18 (34\%) Senior Pharmacists, and 7 (36.8\%) Consultant Pharmacists did not share that concern. Also, 23 (23.9\%) Pharmacists, 6 (11.3\%) Senior Pharmacists, and $2(10.5 \%)$ Consultant Pharmacists do not know about this $(P=0.230)$.

Overall, there was no relationship proven $(\mathrm{P}>0.05)$ between the designation of participants and their perception regarding $\mathrm{PGx}$.

\section{Application of PGx in Pharmacy Practice}

As shown in Table 1, only nine of the total 206 participants had ordered PGx tests recently. Therefore, participants were asked about their reasons for not having done so (Figure 5). In reply, around half of the participants claimed that they did not know which tests needed to be applied, and 40\% simply did not request PGx; whereas, $35 \%$ claimed that the test was not available to them. Only $7.7 \%$ of the participants felt that the time constraints were a barrier for ordering a PGx test (Figure 5).

Twenty to forty percent of participants could relate their knowledge about PGx with their ability to apply the same in their pharmacy practice. A similar proportion felt unable to do the same. The rest of the participants had a neutral inclination toward practical application of PGx in pharmacy practice (Figure 6). Among all participants, 74 $(35.5 \%)$ agree that they can identify the drugs that need pharmacogenetic testing, and $84(40.8 \%)$ believe that they can identify reliable sources of information regarding PGx for healthcare professionals and patients. Besides, only 45 $(21.8 \%)$ of the total participants believe they can readily determine if the required PGx is available within their healthcare system. Less than one-third of the participants $(66,32 \%)$ believe that they can use the PGx results for accurate drug selection, dosing, or monitoring.

When asked about whether any initiatives were taken up by their hospital or government agencies about the practical application of PGx, nearly $38 \%$ of the participants reported that the Saudi government and Saudi FDA have been promoting PGx. However, nearly half of the participants $(102,49.5 \%)$ believe that hospital management does not understand the importance of PGx, and $(76,36.9 \%)$ have no idea whether hospital management understands the importance of PGx (Figure 7). In addition, $128(62.1 \%)$ do not know if there are PGx standards in Saudi Arabia, and $(59,28 \%)$ of the participants deny the existence of PGx standardization (Figure7). 


\section{Reasons for not applying the pharmacogenetic tests by Hospital Pharmacists in Saudi Arabia}

Don't know what test needed

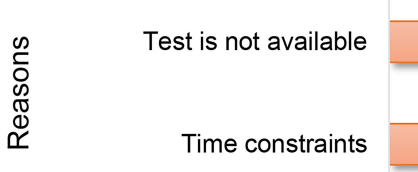

Not requested
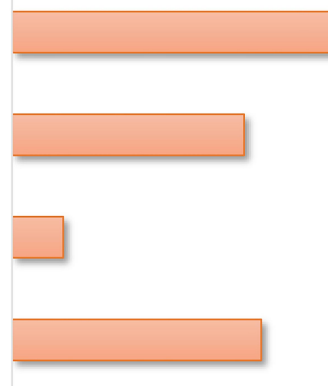

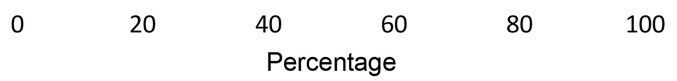

Figure 5 Barriers for not requesting pharmacogenomic testing by the participants in the past year $(\mathrm{N}=18 \mathrm{I})$. Multiple responses by each participant.

\section{Participant's Ability to Apply Pharmacogenomics in Practice}

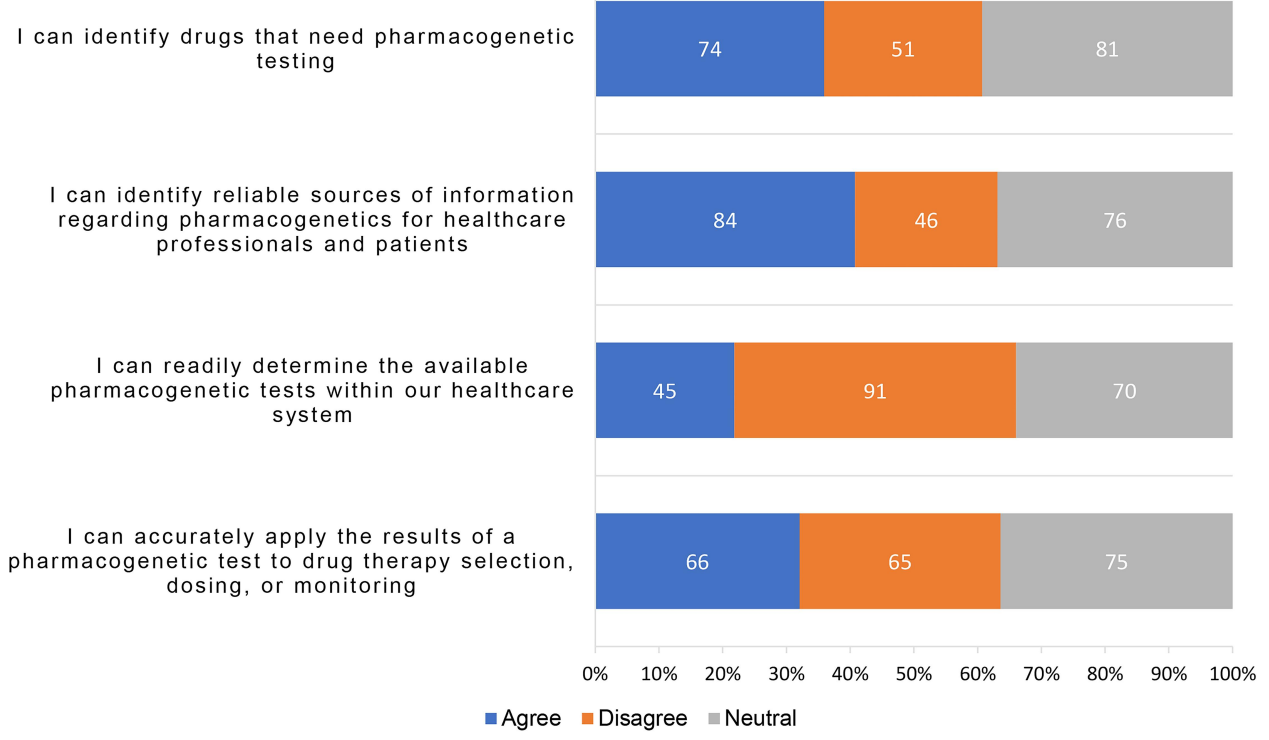

Figure 6 The ability of the participants to apply PGx in clinical practice $(\mathrm{N}=206)$.

Only $(16,7.8 \%)$ of all the participants stated that enough research has been done in the field of PGx in Saudi Arabia, while (96, 46.6\%) of the participants did not believe there was enough research and 94, 45.6\% of the total participants did not have an opinion about whether or not there was adequate research (Figure 7). Also, most $(159,77.2 \%)$ of the participants have not conducted or been part of any research related to PGx; $17(8.3 \%)$ indicated they do not know if they were part of such research, and only 30 (14.6\%) had conducted or been part of any PGx research activity (Figure 7).

\section{Discussion}

Saudi Arabia is one of the developed countries in western Asia, with a population of 34.81 million, and is served by three types of hospitals: MoH hospitals, other governmental hospitals (military and university hospitals), and private hospitals. $^{28}$ The probability of drug-response variations based on genetics is higher in such a populated and developed nation. ${ }^{21}$ Apart from the population, certain factors pertaining to this area play a crucial role in shaping the importance of PGx. Consanguinity marriage is the leading factor in shaping the landscape of genetic disorders in Saudi Arabia. ${ }^{29}$ The high prevalence of genetic disorders 
Pharmacogenomics Status in The Saudi Healthcare System

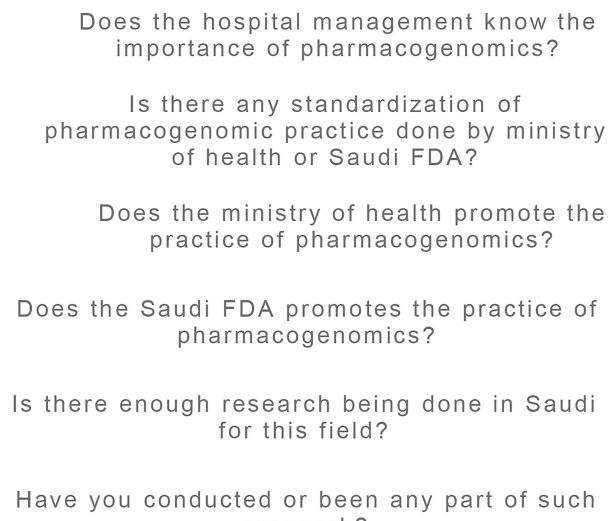

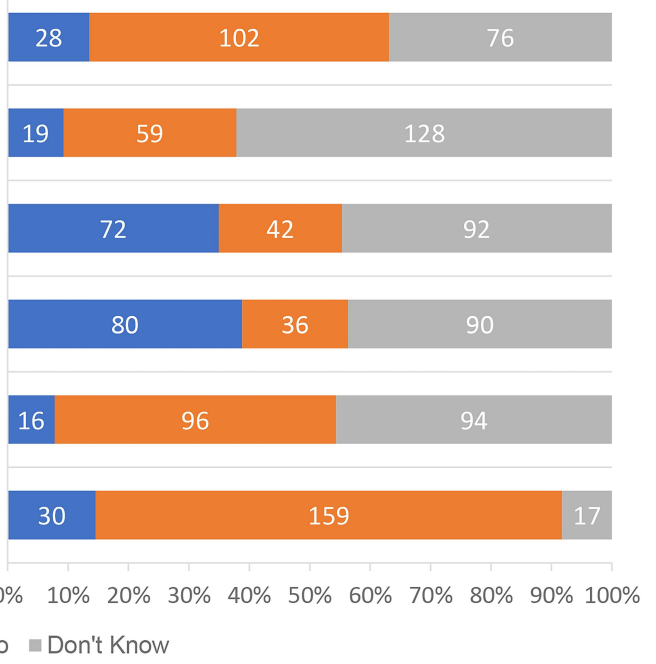

Figure 7 The PGx status within the healthcare system as reported by study participants $(N=206)$.

in the country is also reflected in exclusive Saudi CTGA records. ${ }^{21,27}$

The common prevalent genetic disorders found in Saudi Arabia are blood disorders (sickle cell anemia), congenital malformations, metabolic syndromes, eye and nervous system disorders, and heart disease, as well as digestive system disorders and cancers. ${ }^{21,29}$ The pharmacists have a vital role in such nations, so the current study has explored the factors predicting the knowledge, awareness, and attitude regarding PGx among pharmacists employed in multiple hospitals across Saudi Arabia. ${ }^{21,27}$ Hospital pharmacists work in a well-connected clinical environment, where physicians, pharmacists, and allied clinical staff (laboratory) are collaborating and working together. For that reason, assessing them gives an overall insight about their perceptions, as well as bottlenecks faced in such a setup with regard to PGx implementation. About $70 \%$ of the participants did not receive any formal training on PGx. Most of the participants in the current study were unaware of whether PGx testing is currently available for most medications (42.7\%).

The first observation in this study is that the formal training of pharmacists related to PGx was low, although the participants were educationally qualified. Only 53 participants had either received training or heard about PGx during their pharmacy education (35.8\%), followed by scientific conferences $(22.6 \%)$ and hospital seminars or past research $(15.1 \%)$. This reflects the need for formal training among pharmacists. This finding is concurrent with the participants' knowledge about PGx in pharmacy practice. Based on the knowledge indicators given, participants showed moderate knowledge to some PGx aspects such as the influence of PGx to the patient adherence to medications and the role of PGx to identify drug-drug interactions. Also, the study participants expressed low knowledge to other PGx aspects such as the availability of drug PGx testing and that the genetic determinants affecting the drug response will not change over the patient life.

This weakness in PGx knowledge calls for urgent modification of the pharmacy undergraduate and postgraduate programs to contain more PGx related courses and training. Also, it is essential to develop PGx related continuous medical education programs for the current practising pharmacists. The improvement in education and training is a crucial step to achieve effective implementation of PGx in the Saudi healthcare system.

This finding is concurrent to other studies, in which low awareness reflects the need for education about PGx and its clinical applications in a survey conducted among pharmacists in Qatar and Jordan, and previous surveys conducted among pharmacists and doctors independently. ${ }^{15,16,30}$ This indicates that PGx should be introduced in the curriculum of pharma-related educational courses.

On the other hand, developed nations like the USA have implemented large programs regarding PGx in their medical centers. However, they faced specific challenges, especially in standardizing training programs for pharmacists. ${ }^{8}$ In Europe, the uptake of PGx in clinical settings lags behind, 
facing challenges regarding training programs and education of medical staff along with inadequate lab tests. ${ }^{31,32}$ Also, varying payment and funding structures make the implementation of PGx in clinical settings, and training of pharmacists for the same, challenging as compared to settings in the USA. $^{32}$

Another crucial aspect of this study was the positive perception of the participants toward the practical aspects of PGx. Even though formal training and knowledge were lacking, positive attitudes toward applying PGx in practice call for the implementation of PGx and additional training. Around $85 \%$ of the participants had a positive perception about the practical aspects, such as the role of PGx in service delivery. This positive perception by the study participants could be attributed to their strong belief in the benefit of PGx in the pharmacy practice. The finding is in line with the previous studies. ${ }^{16,33,34}$

Pharmacists also felt that they were capable enough to provide information on the appropriate use of pharmacogenetic testing $(77 \%)$, along with having a say in providing recommendations on the appropriate use of pharmacogenetic testing (70.4\%). Around $83 \%$ felt the need of having knowledge about the concepts. This aspect has been highlighted in some of the previous surveys where pharmacists perceived themselves responsible in the application of PGx to drug therapy selection and monitoring, dosing and monitoring, and patient counseling about medications that may require PGx testing. ${ }^{15,35,36}$ This confidence can be exploited in addition to structured PGx education and training to practice PGx effectively in the Saudi healthcare system.

They also expressed willingness and motivation to learn more about the latest concepts of PGx and its applications. This finding is crucial, as it indicates their significance in providing PGx services. Even previous literature conducted among doctors has reiterated that doctors, too, advocated for the pivotal role of pharmacists in providing PGx, rather than themselves. ${ }^{33,35,36}$ Pharmacists in the current study had high expectations about the role of PGx tests in preventing incorrect drug use, and also said that such tests can be advantageous in revealing risk factors for other diseases, which is concurrent to previous literature. $^{30,37}$

The PGx test adoption was recently ordered $(<6$ months back from the time of the survey) by only eight participants. Participants mainly relate the weak adoption to the lack of knowledge to which test is required and the availability of the test in the healthcare system. The time needed to request PGx tests were not constraints for most of the participants $(92.3 \%)$. Similarly, this confirms that improving PGx education and training in addition to the availability of the PGx tests will ensure effective PGx practice.

Hospital management plays a key role as a decisionmaker to implement PGx in practice and by providing the necessary administrative and financial support. However, around half of the participants reported that their hospital management lacked knowledge about the importance of PGx. Understanding the importance of PGx for the patient benefit and safety will help in the decision to support PGx practice financially and organizationally. Also, this lack of knowledge at the level of hospital administration emphasis to study the role of pharmacy management as middle management to deliver such knowledge.

This finding was further indirectly confirmed by probing about the status of implementation to assess the possibility of any barriers. Many had reported that there were no standardized guidelines issued by the $\mathrm{MoH}$ or Saudi FDA to mandate the use of PGx. Around $38 \%$ of participants reported that the $\mathrm{MoH}$ and Saudi FDA had been promoting PGx. This is a crucial aspect of the strict implementation of PGx. Also, further studies need to explore how the MoH and Saudi FDA are promoting the uptake PGx, and review of existing laws and policies pertaining to the implementation of PGx is needed.

Certain countries, like the USA and the Netherlands, exhibit specific guidelines regarding PGx or have formed working groups proposing guidelines regarding the same. The Royal Dutch Pharmacists Association established the Dutch Pharmacogenetics Working Group (DPWG) in 2005 for aiding in the clinical implementation of PGx and increasing its acceptance. One of the areas where the group aided the implementation of PGx was by providing evidence-based pharmacogenetics guidelines for anticancer drugs and the toxicity associated with them. This guideline focused on starting-dose optimization of three anti-cancer drugs by focusing on the genetic phenotyping of cancer patients (fluoropyrimidines: 5-fluorouracil, capecitabine and tegafur) for the reduction in risk of severe toxicity associated with them. ${ }^{38}$ Despite the structured regulations, a study conducted in the Netherlands explored the implementation barriers among pharmacists by conducting semi-structured interviews. It was revealed that the chief barriers were unclear procedures, insufficient fund reimbursement for PGx testing and consult, lack of evidence for clinical utility, lack of proper infrastructure, and 
lack of knowledge and awareness in healthcare professionals regarding PGx. ${ }^{39}$

The Clinical Pharmacogenetics Implementation Consortium $\left(\right.$ CPIC $\left.^{\circledR}\right)$ managed at Stanford University and St. Jude Children's Research Hospital have issued certain guidelines about the implementation of PGx. These involve standardizing the process of linking genotypes to phenotypes, assigning phenotypes to clinical genotypes, and prescribing recommendations about drugs based on genotype or phenotype. The guideline has also established an SoP, published in Current Drug Metabolism: Incorporation of PGx into Routine Clinical Practice: The Pharmacogenetics Implementation Consortium (CPIC) Guideline Development Process. Further, the FDA (U.S. Food and drug administration) has also worked for better adoption of PGx in clinical settings and better acceptance by patients. ${ }^{40,41}$

However, there were certain bottlenecks, such as a lack of concerned testing facilities at their respective hospitals and a lack of related research. This highlights the need for active role-plays by the national government for promoting and investing in infrastructure related to PGx. Previous studies conducted in Zimbabwe, Malaysia, Nigeria, Indonesia, etc., concurrently emphasized that PGx should be an integral part of the healthcare system. ${ }^{12,15,34}$ However, loopholes like economic disparity, ethical concerns, and training were highlighted for the lapses in implementation.

\section{Strengths and Limitations}

The strength of this study is that it fills the gap for the limited research studies related to PGx in the pharmacy practice of the Saudi health care system. This study considered the first to evaluate the knowledge, perception and the application status of PGx among hospital pharmacist in Saudi hospitals. This preliminary evaluation will provide future insight into the best approach to activate this practice in the Saudi healthcare system. Also, the study covers all types of hospitals and pharmacists with various level of education and designation.

One limitation of the current study is that it used convenience sampling, a form of non-random sampling. Pharmacists who did not identify as a pharmacist on their Twitter account, pharmacists who did not have a Twitter account, and those pharmacists who did not belong to one of the WhatsApp forums on pharmacists' affairs in Saudi Arabia were not invited to participate. Since the authors do not know if the pharmacists who participated have significantly more or less knowledge of PGx than pharmacists who did not participate, we cannot confidently make inferences about the entire population of hospital pharmacists in Saudi Arabia. As the Kingdom of Saudi Arabia is a vast country, it is suggested to provide academic researchers with access to the healthcare workers' official contact emails to ensure random sampling.

\section{Conclusions and Recommendations}

Despite the positive perception shown by the hospital pharmacists toward $\mathrm{PGx}$, only $30 \%$ had received any type of formal training on PGx, and only 9 of them put this in practice the last year before the survey. This positive perception indicates that PGx has the potential to be implemented in the Saudi healthcare system. However, to achieve that there is an urgent need for more integration of PGx related areas in the pharmacy education programs for the future pharmacists and organized continuous training programs for the current practising pharmacists.

Lack of knowledge about the type of PGx test needed and the availability of the PGx test are the major barriers reported by the participants for not requesting a PGx test for the needed patients. The financial support is crucial to make such a PGx test available. However, the majority of the participants stated that hospital managements are unaware of the importance of PGx for patient benefit and safety. This awareness is crucial to obtain the needed financial and administrative support to make such test available.

MoH and Saudi FDA as policy-makers, Saudi commission for health specialities as an accreditor of the continuous medical training programs and pharmacy educational programs need to collaborate and focus on overcoming the identified barriers for effective implementation of PGx in the Saudi healthcare system. Further, in-depth investigation is needed to track the educational and training programs that cause the PGx related low knowledge leading to low adoption of PGx testing. Also, further investigation about the role of pharmacy management to aware the decision-makers about the importance of implementing PGx in clinical practice for the benefit of the patient.

\section{Acknowledgements}

The author would like to express his gratitude to the ministry of education and Najran University, Saudi Arabia for the kind support.

\section{Disclosure}

The author declares no conflict of interest for this work. 


\section{References}

1. Motulsky AG, Qi M. Pharmacogenetics, pharmacogenomics and ecogenetics. J Zhejiang Univ Sci B. 2006;7(2):169-170. doi:10. 1631/jzus.2006.B0169

2. Korngiebel DM, Thummel KE, Burke W. Implementing precision medicine: the ethical challenges. Trends Pharmacol Sci. 2017;38 (1):8-14. doi:10.1016/j.tips.2016.11.007

3. US National Library of Medicine. Genetics home reference, genomic research: what is pharmacogenomics? National Institute of Health, United States of America. Available from: https://ghr.nlm.nih.gov/ primer/genomicresearch/pharmacogenomics. Accessed July 23, 2020.

4. Klein ME, Parvez MM, Shin JG. Clinical implementation of pharmacogenomics for personalized precision medicine: barriers and solutions. J Pharm Sci. 2017;106(9):2368-2379. doi:10.1016/j. xphs.2017.04.051

5. Roden DM, McLeod HL, Relling MV, et al. Pharmacogenomics. Lancet. 2019;394(10197):521-532. doi:10.1016/S0140-6736(19)312 76-0

6. Ehmann F, Caneva L, Prasad K, et al. Pharmacogenomic information in drug labels: European Medicines Agency perspective. Pharmacogenomics J. 2015;15(3):201-210. doi:10.1038/tpj.2014.86

7. Peterson JF, Field JR, Shi Y, et al. Attitudes of clinicians following large-scale pharmacogenomics implementation. Pharmacogenomics J. 2016;16(4):393-398. doi:10.1038/tpj.2015.57

8. Murphy JE, Green JS, Adams LA, Squire RB, Kuo GM, Mckay A. Pharmacogenomics in the curricula of colleges and schools of pharmacy in the United States. Am J Pharm Educ. 2010;74(1):7. doi:10.5688/aj740107

9. Kuo GM, Ma JD, Lee KC, et al. Institutional profile: University of California San Diego Pharmacogenomics Education Program $\left(\right.$ PharmGenEd $\left.{ }^{\mathrm{TM}}\right)$ : bridging the gap between science and practice. Pharmacogenomics. 2011;12(2):149-153. doi:10.2217/pgs.10.213

10. Lee KC, Hudmon KS, Ma JD, Kuo GM. Evaluation of a shared pharmacogenomics curriculum for pharmacy students. Pharmacogenomics. 2015;16(4):315-322. doi:10.2217/pgs.14.181

11. McMahon T, Tucci J. The perceptions of pharmacists in Victoria, Australia on pharmacogenetics and its implications. Pharm Pract (Granada). 2011;9(3):141-147. doi:10.4321/S1886-3655201100030 0005

12. Muzoriana N, Gavi S, Nembaware V, Dhoro M, Matimba A. Knowledge, attitude, and perceptions of pharmacists and pharmacy students towards pharmacogenomics in Zimbabwe. Pharmacy. 2017;5(4):36. doi:10.3390/pharmacy5030036

13. Yau A, Aziz ABA, Haque M. Knowledge, attitude and practice concerning pharmacogenomics among pharmacists: a systematic review. J Young Pharm. 2015;7(3):145-154. doi:10.5530/jyp.20 15.3.3

14. Tuteja S, Haynes K, Zayac C, Sprague JE, Bernhardt B, Pyeritz R. Community pharmacists' attitudes towards clinical utility and ethical implications of pharmacogenetic testing. Per Med. 2013;10 (8):793-800. doi:10.2217/pme.13.85

15. Da P, Sl N, Bp S, Knowledge TSK. Awareness and attitude of pharmacists toward pharmacogenetic practice: perspective of community and hospital in Yogyakarta, Indonesia. J Community Med Health Educ. 2017;07(06):1-10. doi:10.4172/2161-0711.1000568

16. Elewa H, Alkhiyami D, Alsahan D, Abdel-Aziz A. A survey on the awareness and attitude of pharmacists and doctors towards the application of pharmacogenomics and its challenges in Qatar. J Eval Clin Pract. 2015;21(4):703-709. doi:10.1111/jep.12372

17. Owusu-Obeng A, Weitzel KW, Hatton RC, et al. Emerging roles for pharmacists in clinical implementation of pharmacogenomics. Pharmacotherapy. 2014;34(10):1102-1112. doi:10.1002/phar.1481

18. El-Ibiary SY, Cheng C, Alldredge B. Potential roles for pharmacists in pharmacogenetics. J Am Pharm Assoc. 2008;48(2):e21-e32. doi:10.1331/JAPhA.2008.07050
19. Center for Arab Genomic Studies A division of Sheikh Hamdan award for medical sciences. Available from: http://cags.org.ae/. Accessed July 25, 2020.

20. CTGA. The Database for Genetic Disorders in Arabs. Accessed July 25, 2020. Available from: http://www.cags.org.ae/ctgaguide3c2.pdf.

21. Abu-Elmagd M, Assidi M, Schulten HJ, et al. Individualized medicine enabled by genomics in Saudi Arabia. BMC Genomics. 2015;8 (1):24-27. doi:10.1186/1755-8794-8-S1-S3

22. Medicine MAAA-MEJ of F, 2004 undefined. Common genetics and metabolic diseases in Saudi Arabia. mejfm.com. Accessed July 25, 2020. Available from: http://www.mejfm.com/journal/Jul2004/ CommonGenetics andMeta.pdf.

23. Kirchheiner J, Roots I, Goldammer M, Rosenkranz B, Brockmöller J. Effect of genetic polymorphisms in cytochrome P450 (CYP) 2C9 and CYP2C8 on the pharmacokinetics of oral antidiabetic drugs: clinical relevance. Clin Pharmacokinet. 2005;44(12):1209-1225. doi:10.216 5/00003088-200544120-00002

24. Zhang X, Li L, Ding X, Kaminsky LS. Identification of cytochrome P450 oxidoreductase gene variants that are significantly associated with the interindividual variations in warfarin maintenance dose. Drug Metab Dispos. 2011;39(8):1433-1439. doi:10.1124/dmd.111.038836

25. Saour JN, Shereen AW, Saour BJ, Mammo LA. CYP2C9 polymorphism studies in the Saudi population. Saudi Med J. 2011;32(4):347-352.

26. Alzahrani A, Ragia G HH-B research, 2013 undefined. Genotyping of CYP2C9 and VKORC1 in the Arabic population of Al-Ahsa, Saudi Arabia. hindawi.com. Available from: https://www.hindawi.com/jour nals/bmri/2013/315980/abs/. Accessed August 3, 2020.

27. Bizzari S, Qari A, Balobaid A, et al. Genetic Disorders in Saudi Arabia: A CTGA Perspective.

28. Ministry of Health. Statistical Yearbook 2018. Kingdom of Saudi Arabia. Accessed July 23, 2020. Available from: https://www.moh. gov.sa/en/Ministry/Statistics/book/Pages/default.aspx.

29. MI El M, Al S, Al H, Qurachi MM, Al O. Consanguinity and major genetic disorders in Saudi children: a community-based cross-sectional study. Ann Saudi Med. 2008;28(3):169. doi:10.5144/ 0256-4947.2008.169

30. Alejielat R, Ejielat Z, Andrawes S, Mhaidat NM. An evaluation of the knowledge, opinions, expectations and concerns toward pharmacogenomics among Jordanian pharmacists. Per Med. 2016;13 (2):143-154. doi:10.2217/pme.15.50

31. Just KS, Steffens M, Swen JJ, Patrinos GP, Guchelaar HJ, Stingl JC. Medical education in pharmacogenomics - results from a survey on pharmacogenetic knowledge in healthcare professionals within the European pharmacogenomics clinical implementation project Ubiquitous Pharmacogenomics (U-PGx). Eur J Clin Pharmacol. 2017;73(10):1247-1252. doi:10.1007/s00228-017-2292-5

32. Gurwitz D, Zika E, Hopkins MM. Pharmacogenetics in Europe: barriers and opportunities. Public Health Genomics. 2009;12(3). doi: $10.1159 / 000189625$

33. Mccullough KB, Formea CM, Berg KD, et al. Assessment of the pharmacogenomics educational needs of pharmacists. Am J Pharm Educ. 2011;75(3):3. doi:10.5688/ajpe75351

34. Lay Kek T, Alam P. IMJM Pharmacogenomics based practice in Malaysia: the attitude, knowledge and adoption by the healthcare professionals. Int Med J Malaysia. 2014;13.

35. Mills R, Haga SB. Clinical delivery of pharmacogenetic testing services: a proposed partnership between genetic counselors and pharmacists. Pharmacogenomics. 2013;14(8):957-968. doi:10.2217/ pgs. 13.76

36. Williams MS. Genomic medicine implementation: learning by example. Am J Med Genet Part C Semin Med Genet. 2014;166 (1):8-14. doi:10.1002/ajmg.c.31394

37. Albassam A, Alshammari S, Ouda G, Koshy S, Awad A. Knowledge, perceptions and confidence of physicians and pharmacists towards pharmacogenetics practice in Kuwait. PLoS One. 2018;13(9): e0203033. doi:10.1371/journal.pone.0203033 
38. Lunenburg CATC, van der Wouden $\mathrm{CH}$, Nijenhuis $\mathrm{M}$, et al. Dutch Pharmacogenetics Working Group (DPWG) guideline for the genedrug interaction of DPYD and fluoropyrimidines. Eur J Hum Genet. 2020;28(4):508-517. doi:10.1038/s41431-019-0540-0

39. van der Wouden $\mathrm{CH}$, Paasman E, Teichert $\mathrm{M}$, Crone MR, Guchelaar H-J, Swen JJ. Assessing the implementation of pharmacogenomic panel-testing in primary care in the Netherlands utilizing a theoretical framework. J Clin Med. 2020;9(3):814. doi:10.3390/ jem9030814
40. First FDA-approved medicine manufactured using $3 \mathrm{~d}$ printing technology now available spritam ${ }^{\circledR}$ is designed to transform experience of taking epilepsy medication. Available from: https://www.aprecia. com/pdf/ApreciaSPRITAMLaunchPressRelease_FINAL.PDF.

Accessed February 24, 2018.

41. Desta Z, Gammal RS, Gong L, et al. Clinical pharmacogenetics implementation consortium (CPIC) guideline for cyp2b6 and efavirenz-containing antiretroviral therapy. Clin Pharmacol Ther. 2019;106(4):726-733. doi:10.1002/cpt.1477

\section{Publish your work in this journal}

Risk Management and Healthcare Policy is an international, peerreviewed, open access journal focusing on all aspects of public health, policy, and preventative measures to promote good health and improve morbidity and mortality in the population. The journa welcomes submitted papers covering original research, basic science, clinical \& epidemiological studies, reviews and evaluations, guidelines, expert opinion and commentary, case reports and extended reports. The manuscript management system is completely online and includes a very quick and fair peer-review system, which is all easy to use. Visit http://www.dovepress.com/testimonials.php to read real quotes from published authors.

Submit your manuscript here: https://www.dovepress.com/risk-management-and-healthcare-policy-journal 